\title{
Chair's Letter - May 2004
}

\author{
Pat Smedley
}

$\mathrm{O}$ UR conference this year 'Developing Roles in Perianaesthesia' focuses on the fast moving and radical changes affecting the entire health service but in particular, the perioperative area. Breaking down traditional professional boundaries has opened up the possibility for nurses and theatre technicians alike to extend their scope of practice to delivery of anaesthesia under supervision. For health care assistants the formulation of new national occupational standards with clumps of clinical skills to be had for the training has opened up the ladder to continuing professional advancement. Operating department practitioners will claim full registration and diploma status as their start point. Post registration training both for nurses and technicians alike may well shift to become a shared pathway. The name 'nurse' is already disappearing in some departments.

Maybe it doesn't matter what one is called - if the patient care delivered is of the highest quality. I remain suspicious however of any new trend/big idea - which may threaten my profession - nursing. Threatened is a strong word to use here - and maybe it is not justified. However, I do feel unease when so many changes are pushed through as part. of a speedy political agenda. I welcome every chance for each member of the perioperative team to be trained to the most excellent degree to deliver first class patient care. I think, however, we need to be very careful which skills are given over to which members of the health care team. The anaesthetic and recovery domains are acute areas where any patient intervention may have consequences not seen on the wards. Before we make over any duties to health care assistants within PACU, for example, lets be very sure that they are appropriate. We have inherited one hundred and fifty years of progress towards full professional status as nurses in the UK. It takes more than pulling together bundles of skills to create a rounded professional.

This year we will present our clinical competencies for the first time. While the new National Occupational Standards will be extremely useful as structures to guide skills training for the unqualified staff - our clinical competencies present much more detail for the qualified practitioner and I believe many of our members will find them extremely useful for pay banding, local standard setting/audit, staff assessment and training.

We hope to see as many members of the association as possible in Hove Town Hall in June. As usual, we have a very full programme. Apologies to all those last year who thought we had too much choice - and they could not get to all the sessions that interested them. Well - actually no apologies - we believe in giving our delegates an exciting mixture of events to chose from plus an excellent commercial exhibition. Looking forward to meeting you soon - wandering around conference - drinking a glass of wine at our reception - meeting you in the evening for fish and chips - informality with style is our speciality. 